\title{
Performance Analysis of a Heat Pipe with Stainless Steel Wick
}

\author{
Md Enamul Haque ${ }^{1}$, Md Efthakher Hossain ${ }^{2}$ and Mohammad Mashud ${ }^{2}$ \\ ${ }^{1}$ Department of Mechanical Engineering, Konya Technical University, Konya, Turkey \\ ${ }^{2}$ Department of Mechanical Engineering, Khulna University of Engineering \& Technology, Khulna-9203, BANGLADESH
}

Received: March 24, 2020, Revised: April 03, 2020, Accepted: April 03, 2020, Available Online: April 05, 2020

\begin{abstract}
In this study, the influences of different parameters on performance of a heat pipe with stainless steel net as wick have been presented. Experiments have been carried out for an input power range from $80 \mathrm{~W}$ to $160 \mathrm{~W}$, constant cooling water mass flow rate of 0.0515 liter/s, and constant temperature at the inlet to condenser of $11^{\circ} \mathrm{C}$. The temperatures were recorded at different power level by using a laser thermometer of the heater block, evaporator and condenser end at 50 second interval. Variation in the input power was done by varying the input voltage. It was done by a variack. Considering all criteria the copper is selected as the material of the container, water is selected as the working fluid of the heat pipe, stainless steel net is used as wick material. As copper/water heat pipes are able to tolerate storage temperatures between $-65^{\circ} \mathrm{C}$ and $250^{\circ} \mathrm{C}$, and can effectively operate between $10^{\circ} \mathrm{C}$ and $250^{\circ} \mathrm{C}$. So a $.9144 \mathrm{~m}$ copper tube is used to construct the heat pipe. Inside this tube stainless steel net is used as wick material to aid the flow of fluid. In the observation it is observed that the temperature of the evaporator end increases at a greater rate of the copper pipe than the heat pipe at different power level. It has been shown the variation of temperature of the heater block and the evaporator section at $80 \mathrm{~V}, 100 \mathrm{~V}, 120 \mathrm{~V}$, $140 \mathrm{~V}, 160 \mathrm{~V}$ respectively of the heat pipe and copper pipe.
\end{abstract}

Keywords: Heat Transfer; Stainless Steel Net; Copper Heat Pipe; Water Heat Pipe.

This work is licensed under a Creative Commons Attribution-NonCommercial 4.0 International

\section{Introduction}

The concept of heat pipes was introduced by R.S. Gaugler in 1940's. But, it was in 1984 that Cotter first introduced the idea of "micro" heat pipes [1]. Transportation of heat is one of the most difficult and inefficient tasks in thermal management [2]. It often results in costly heat transfer losses and reduced overall efficiency [3]. The performance of various mechanical and electrical components depends on the performance of the cooling system, because during operation they generate heat and dissipation of this heat is necessary for their optimum and reliable operation [2]. Many of today's electronic devices require cooling beyond the capabilities of standard metallic heat sinks. Cooling problems in micro electric circuits are generally critical because the generated heat must be dissipated from such small surface areas [4]. Heat transfer by heat pipes is one of the fastest and most efficient methods for thermal management. They offer a high efficiency, passive, compact heat transfer solution and are rapidly becoming a mainstream thermal management tool [5].

\section{Historical Background of Heat Pipe}

The development of the heat pipe originally started with Angier March Perkins who worked initially with the concept of the working fluid only in one phase [8]. Jacob Perkins patented the Perkins Tube in 1936 and they became widespread for use in locomotive boilers and baking ovens. The Perkins Tube was the jumping off point for the development of the modern heat pipe. The concept of the modern heat pipe, which relied on a wicking system to transport the liquid against gravity and up to the condenser, was put forward by R.S. Gaugler of the General Motors Corporation in 1942 [1]. In 1944, Gaugler described how his heat pipe would be applied to refrigeration systems. Heat pipe research became popular after that and many industries and labs including Los Alamos, RCA, the Joint Nuclear Research Centre in Italy, began to apply heat pipe technology their fields. They have been a subject since the early1950s and are commercially available in a variety of forms [6]. In 1963 George Grover, an engineer of Los Alamos National Research Laboratory, demonstrated the first heat pipe. By 1969, there was a vast amount of interest on the part of NASA, Hughes, the European Space Agency, and other aircraft companies in regulating the temperature of a spacecraft and how that could be done with the help of heat pipes [9]. There has been extensive research done to date regarding specific heat transfer characteristics, in addition to the analysis of various material properties and geometries [8][10].

\section{Working Principle of Heat Pipe}

A heat pipe broadly divided in three sections namely, evaporator, adiabatic and condenser [7]. Heat pipes employ evaporative cooling to transfer thermal energy from one point to another by the evaporation and condensation of a working fluid or coolant. Heat pipes rely on a temperature difference between the ends of the pipe [2]. When one end of the heat pipe is heated the working fluid inside the pipe at that end evaporates and increases the vapor pressure inside the cavity of the heat pipe [4]. The latent heat of evaporation absorbed by the vaporization of the working fluid reduces the temperature at the hot end of the pipe .The vapor pressure over the hot liquid working fluid at the hot end of the pipe is higher than the equilibrium vapor pressure over condensing working fluid at the cooler end of the pipe, and this pressure difference drives a rapid mass transfer to the 
condensing end where the excess vapor releases its latent heat, warming the cool end of the pipe [4]. The condensed working fluid then flows back to the hot end of the pipe, either by force of gravity in the case of vertically oriented heat pipes, or through capillary action in the case of heat pipes containing wicks, or heat pipes that are orientated horizontally relative to gravity. In summary inside a heat pipe "hot" vapor flows in one direction, condenses to the liquid phase which flows back in the other direction to evaporate again and close the cycle.

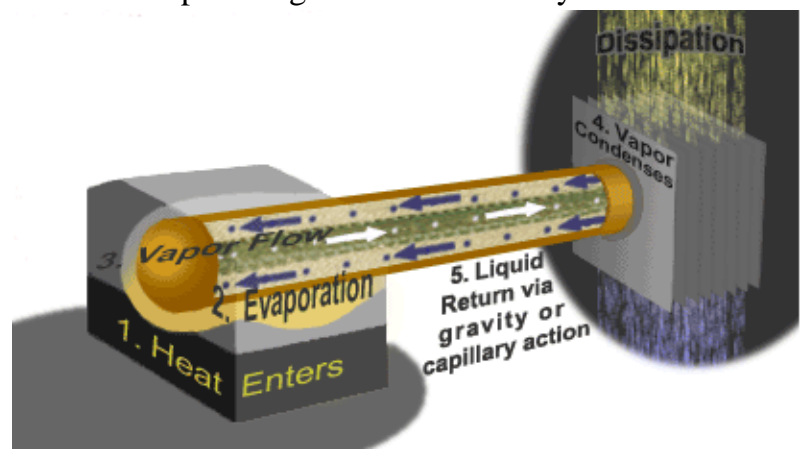

Fig. 1 Working principle of Heat Pipe [4]

\section{Performance Evaluation}

The performance evaluation of a heat pipe is necessary step that has to be often repeated in order to characterize many factors such as working temperature and maximum heat transfer capacity. The heat pipe performance is usually defined in terms of the temperature drop across the working length of heat pipe at a given power level. If $\mathrm{Q}$ is the heat load on the system and $\Delta \mathrm{T}$ is the temperature drop across the heat pipe then the resistance $\mathrm{R}$ is the given by [5],

$R=\frac{\Delta T}{Q}$

The relation shown in the above equation is a derivative of the classic conduction equation,

$Q=\frac{K \cdot A \cdot \Delta T}{L}$

It is clear that resistance $\mathrm{R}$ is defined as,

$R=\frac{L}{K \cdot A}$

During this work the heat pipe performance was performance was measured in terms of conductance. In a way this measured quantity is similar to material thermal conductivity.

\section{Design Considerations}

Heat pipes must be tuned to particular cooling conditions. The choice of pipe material, size and coolant all have an effect on the optimal temperatures in which heat pipes work.

The three basic components of a heat pipe are:

Container, working fluid, wick or capillary structure [2].

To construct a heat pipe the following steps have to be followed:

(i). Determination of the working fluid appropriate for the application.

(ii). Selection of the pipe material compatible to the working fluid.

(ii). Selection of the wick structure for the operating orientation.
Table 1 Typical Operating Characteristics of Heat Pipes [20]

\begin{tabular}{|c|c|c|c|c|}
\hline 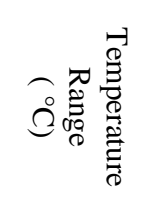 & 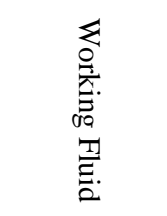 & 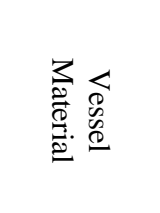 & 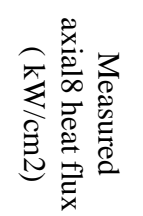 & 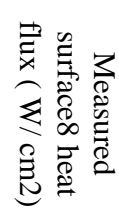 \\
\hline $\begin{array}{l}-200 \text { to }- \\
80\end{array}$ & $\begin{array}{l}\text { Liquid } \\
\text { Nitrogen }\end{array}$ & $\begin{array}{l}\text { Stainless } \\
\text { Steel }\end{array}$ & $\begin{array}{l}0.067 @- \\
163^{\circ} \mathrm{C}\end{array}$ & $\begin{array}{l}1.01 \\
@- \\
16^{\circ} 3 \mathrm{C}\end{array}$ \\
\hline-70 to +60 & $\begin{array}{l}\text { Liquid } \\
\text { Ammonia }\end{array}$ & $\begin{array}{l}\text { Nickel, } \\
\text { Aluminum, } \\
\text { Stainless } \\
\text { Steel }\end{array}$ & 0.295 & 2.95 \\
\hline $\begin{array}{l}-45 \text { to } \\
+120\end{array}$ & $\begin{array}{l}\text { Methanol } \\
\text { Copper, } \\
\text { Nickel, } \\
\text { Stainless } \\
\text { Steel }\end{array}$ & $\begin{array}{l}\text { Copper, } \\
\text { Nickel, } \\
\text { Stainless } \\
\text { Steel }\end{array}$ & $\begin{array}{l}0.45 @ \\
100^{\circ} \mathrm{Cx}\end{array}$ & $\begin{array}{l}75.5 @ \\
100^{\circ} \mathrm{C}\end{array}$ \\
\hline $\begin{array}{l}+5 \text { to } \\
+230\end{array}$ & Water & $\begin{array}{l}\text { Copper, } \\
\text { Nickel }\end{array}$ & $\begin{array}{l}0.67 @ \\
200^{\circ} \mathrm{C}\end{array}$ & $\begin{array}{l}146 @ \\
170^{\circ} \mathrm{C}\end{array}$ \\
\hline $\begin{array}{l}+190 \text { to } \\
+550\end{array}$ & $\begin{array}{l}\text { Mercury* } \\
+0.02 \% \\
\text { Magnesium } \\
+0.001 \%\end{array}$ & $\begin{array}{l}\text { Stainless } \\
\text { Steel }\end{array}$ & $\begin{array}{l}25.1 @ \\
360^{\circ} \mathrm{C}^{*}\end{array}$ & $\begin{array}{l}181 @ \\
750^{\circ} \mathrm{C}\end{array}$ \\
\hline $\begin{array}{l}+400 \text { to } \\
+800\end{array}$ & Potassium* & $\begin{array}{l}\text { Nickel, } \\
\text { Stainless } \\
\text { Steel }\end{array}$ & $\begin{array}{l}5.6 @ \\
750^{\circ} \mathrm{C}\end{array}$ & $\begin{array}{l}181 @ \\
750^{\circ} \mathrm{C}\end{array}$ \\
\hline $\begin{array}{l}+500 \text { to } \\
+900\end{array}$ & Sodium* & $\begin{array}{l}\text { Nickel, } \\
\text { Stainless } \\
\text { Steel }\end{array}$ & $\begin{array}{l}9.3 @ \\
850^{\circ} \mathrm{C}\end{array}$ & $\begin{array}{l}224 @ \\
76^{\circ} 0 \mathrm{C}\end{array}$ \\
\hline $\begin{array}{l}+900 \text { to } \\
+1,500\end{array}$ & Lithium* & $\begin{array}{l}\text { Niobium } \\
+1 \% \\
\text { Zirconium }\end{array}$ & $\begin{array}{l}2.0 @ \\
1250^{\circ} \mathrm{C}\end{array}$ & $\begin{array}{l}207 @ \\
1250^{\circ} \mathrm{C}\end{array}$ \\
\hline $\begin{array}{l}1,500+ \\
2,000\end{array}$ & Silver & $\begin{array}{l}\text { Tantalum } \\
+5 \% \\
\text { Tungsten }\end{array}$ & 4.1 & 413 \\
\hline
\end{tabular}

\subsection{Container}

The function of the container is to isolate the working fluid from the outside environment. It has to therefore be leak-proof, maintain the pressure differential across its walls, and enable transfer of heat to take place from and into the working fluid. Selection of the container material depends on many factors.

These are as follows [4]:

- Compatibility (both with working fluid and external environment)

- Strength to weight ratio

- Thermal conductivity

- Ease of fabrication, including welding, machine ability and ductility

- Porosity

- Wet ability

Most of the above are self-explanatory. A high strength to weight ratio is more important in spacecraft applications. The material should be non-porous to prevent the diffusion of vapor. A high thermal conductivity ensures minimum temperature drop between the heat source and the wick [9]. 
Considering the criteria, described above and from the table for the temperature range $5^{\circ} \mathrm{C}$ to $230^{\circ} \mathrm{C}$ [11], we select a copper as the material of the container.

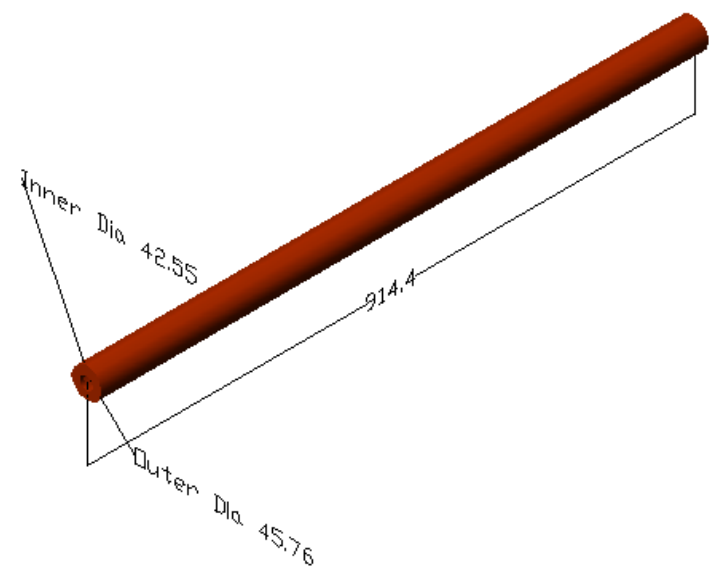

Fig. 2 Container (all the dimensions are in millimeter)

\subsection{Working Fluid}

A particular working fluid can only be functional at certain temperature ranges. Also, the particular working fluid needs a compatible vessel material to prevent corrosion or chemical reaction between the fluid and the vessel. Corrosion will damage the vessel and chemical reaction can produce a noncondensable gas [12].

A first consideration in the identification of a suitable working fluid is the operating vapor temperature range. Within the approximate temperature band, several possible working fluids may exist, and a variety of characteristics must be examined in order to determine the most acceptable of these fluids for the application considered [12]-[13].

The prime requirements are:

- $\quad$ Compatibility with wick and wall materials

- Good thermal stability

- Wet ability of wick and wall materials

- Vapor pressure not too high or low over the operating temperature range

- High latent heat

- High thermal conductivity

- Low liquid and vapor viscosities

- High surface tension

- Acceptable freezing or pour point

The selection of the working fluid must also be based on thermodynamic considerations which are concerned with the various limitations to heat flow occurring within the heat pipe like, viscous, sonic, capillary, entrainment and nucleate boiling levels.

In heat pipe design, a high value of surface tension is desirable in order to enable the heat pipe to operate against gravity and to generate a high capillary driving force. In addition to high surface tension, it is necessary for the working fluid to wet the wick and the container material i.e. contact angle should be zero or very small. The vapor pressure over the operating temperature range must be sufficiently great to avoid high vapor velocities, which tend to setup large temperature gradient and cause flow instabilities.
A high latent heat of vaporization is desirable in order to transfer large amounts of heat with minimum fluid flow, and hence to maintain low pressure drops within the heat pipe. The thermal conductivity of the working fluid should preferably be high in order to minimize the radial temperature gradient and to reduce the possibility of nucleate boiling at the wick or wall surface. The resistance to fluid flow will be minimized by choosing fluids with low values of vapor and liquid viscosities.

Considering the criteria, described above and from the table for the temperature range $5^{\circ} \mathrm{C}$ to $230^{\circ} \mathrm{C}$ and for the copper container, water is selected as the working fluid of the Heat Pipe [14].

The mount of working fluid is calculated as follows:

Length of the evaporator, $\mathrm{L}=.1524 \mathrm{~m}$

Radius of the cylinder, $\mathrm{r}=0.021275 \mathrm{~m}$

Volume of the section $\mathrm{V}=\pi r^{2} \mathrm{~L}=.000086683 \mathrm{~m}^{3}$

So, the volume of working fluid, $v=0.086683 \mathrm{Ltr}$.

\subsection{Wick or Capillary Structure}

The wick provides the capillary driving force to return the condensate to the evaporator [1]. The quality and type of wick usually determines the performance of the heat pipe, for this is the heart of the product. Different types of wicks are used depending on the application for which the heat pipe is being used. It is a porous structure made of materials like steel, aluminum, nickel or copper in various ranges of pore sizes [2]. They are fabricated using metal foams, and more particularly felts, the latter being more frequently used. By varying the pressure on the felt during assembly, various pore sizes can be produced. By incorporating removable metal mandrels, an arterial structure can also be molded in the felt [16].

Fibrous materials, like ceramics, have also been used widely. They generally have smaller pores. The main disadvantage of ceramic fibers is that, they have little stiffness and usually require a continuous support by a metal mesh [3]. Thus while the fibre itself may be chemically compatible with the working fluids, the supporting materials may cause problems. More recently, interest has turned to carbon fibres as a wick material. Carbon fibre filaments have many fine longitudinal grooves on their surface, have high capillary pressures and are chemically stable. A number of heat pipes that have been successfully constructed using carbon fibre wicks seem to show a greater heat transport capability [17].

The prime purpose of the wick is to generate capillary pressure to transport the working fluid from the condenser to the evaporator. It must also be able to distribute the liquid around the evaporator section to any area where heat is likely to be received by the heat pipe. Often these two functions require wicks of different forms. The selection of the wick for a heat pipe depends on many factors, several of which are closely linked to the properties of the working fluid [17].

The maximum capillary head generated by a wick increases with decrease in pore size. The wick permeability increases with increasing pore size. Another feature of the wick, which must be optimized, is its thickness. The heat transport capability of the heat pipe is raised by increasing the wick thickness. The overall thermal resistance at the evaporator also depends on the conductivity of the working fluid in the wick. Other necessary properties of the wick are compatibility with the working fluid and wet ability. The most common types of 
wicks that are used are Sintered Powder, Grooved Tube, and Screen Mesh etc [16].

For the construction of the heat pipe, considering above criteria and the temperature range, container material and working fluid, Stainless steel net is used as wick material.

\subsection{Materials Used}

- Copper pipe as container.

- Water as working fluid

- Stainless steel net as wick material.

- One aluminium pipe

- Two nipples.

- Two gate valves

- Mika

- Nicrome wire.

- Asbestos rope.

- Glass wool.

- Metal sheet.

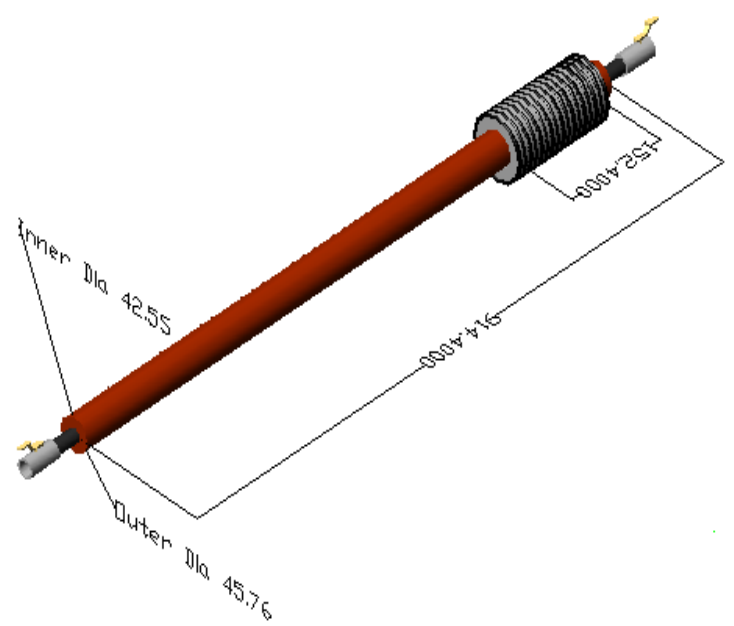

Fig. 3 Heat Pipe (All the dimensions are in millimeter)

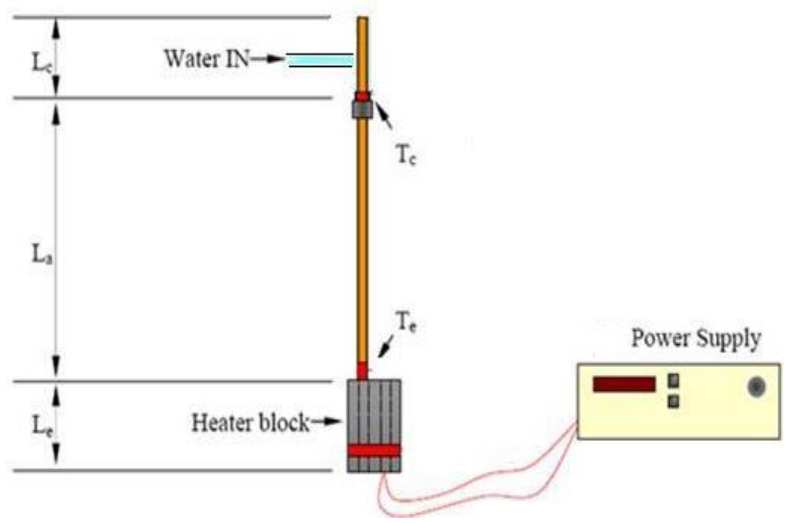

Fig. 4 Setup for Heat pipe's performance test

\section{Construction Procedure}

Heat pipes are generally composed of a tube, closed on each end, with fluid in it. As copper/water heat pipes are able to tolerate storage temperatures between $-65^{\circ} \mathrm{C}$ and $250^{\circ} \mathrm{C}$, and can effectively operate between $10^{\circ} \mathrm{C}$ and $250^{\circ} \mathrm{C}$. So a $.9144 \mathrm{~m}$ copper tube is used to construct the heat pipe. Inside this tube stainless steel net is used as wick material to aid the flow of fluid. Water is used as working fluid. The two end of the tube are sealed by welding one copper sheet on each end of the tube. One small hole is made on each of the two sheets by drilling machine. One nipple is welled on each of the two holes. Then one get valve is placed on each nipple. One gate valve is connected with vacuumer and another valve is connected with a pipe which is submerged in the liquid filled beaker. A six inch aluminum tube is placed on one end of the copper tube. It works as the heater block. This tube is covered by mica to prevent passing of electricity from the heating coil to the aluminum tube as well as to the copper tube. Nicrome wire is used as heating coil which is spiraled through the aluminum tube. Then the coil is covered by mica and finally by asbestos rope. The coil is connected with wire through which electricity can pass through it. A certain portion of the copper pipe is covered with glass wool for preventing the transfer of heat.

\section{Testing Procedure}

The heat pipe was subjected to a heat load across its working length. The heater block was powered by electricity. Its power input was controlled by a regulated power supply. Heat was extracted by water. The flow rate and temperature of the supplied water was kept constant. The temperature of the supplied water was $11^{\circ} \mathrm{C}$. The flow rate of the supplied water was 0515 LiterlSec. The setup is shown in Fig. 4. Temperatures were recorded at different power level by using a laser thermometer of the heater block, evaporator and condenser end at 50 second interval. Variation in the input power was done by varying the input voltage. It was done by a variack.

\subsection{Measurement Error and Losses}

The measurement of thermal conductance is complicated by a number of other parameters not related to the physical state of the material. The nature of the test setup affects the data reduction due to various losses and leakages of the applied heat load. Thermal contact resistance is one of the major causes of heat loss in a test setup. It depends on factors such as pressure, surface roughness and hardness etc. Contact resistance comes into importance at two points in the setup, the contact between electrical heaters and heater block and contact resistance between heater block and the test subject.

The heat is transmitted across the interfacial contacts by conduction, through the air trapped in the gap and via radiation. Thermal resistance is caused by oxidation of contacting surfaces, and radiation heat transfer between microscopic voids due to surface roughness. Additionally, heat loss through the insulation also adds to the parasitic losses in the system. The heat supplied by the heaters, Q, is split into,

- $Q_{\text {Heater } \text { block }}=$ Heat dissipated by the heater block.

- $Q_{\text {Insulation }}=$ Heat loss through the insulation.

- $Q_{\text {Adiabatic }}=$ Heat loss through the adiabatic section.

- $Q_{\text {Condenser }}=$ Heat rejected to circulating water.

$\mathrm{Q}=Q_{\text {Heater block }}+Q_{\text {Insulation }}+Q_{\text {Adiabatic }}+Q_{\text {Condenser }}[18]$

Assuming that the condenser rejects all the heat to circulating water $Q_{\text {Condenser }}$ is the actual heat heat transferred through the heat pipe and all others are lost through the system. As shown in equation, since all of these are included in the 
evaluation of heat pipe conductance, it introduces a corresponding error in recording of data.

The other factors that directly contribute to heat loss include errors in the measurement of input power and recorded temperatures. Also the variation in the temperature of cooling water is unpredictable. The changes in surrounding conditions increase or decrease the heat loss to the heat loss to the environment.

It is obvious that a number of such systematic errors are present in testing and that any reporting of thermal conductance of the heat pipe is subjective to the viewpoint of the person conducting test. Under such conditions, there is a possibility of disagreement in the results for tests conducted at different periods of time on the same test subject using the same test setup.

\section{Results}

Table 2 Results for Copper pipe

\begin{tabular}{|c|c|c|c|c|c|}
\hline $\begin{array}{l}0 \\
\text { o } \\
z \\
0\end{array}$ & 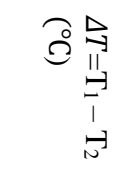 & 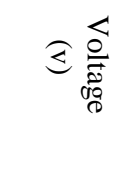 & 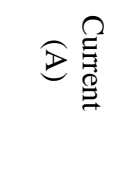 & 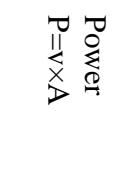 & $\xi^{\circ}$ \\
\hline 1 & 36.1 & 80 & 5.38 & 430.4 & 1836.45 \\
\hline 2 & 39 & 80 & 5.38 & 430.4 & 1981.89 \\
\hline 3 & 42 & 80 & 5.38 & 430.4 & 2131.59 \\
\hline 4 & 43.1 & 80 & 5.38 & 430.4 & 2184.19 \\
\hline 5 & 41.9 & 80 & 5.38 & 430.4 & 2121.22 \\
\hline 6 & 44.3 & 100 & 5.66 & 566 & 2240.51 \\
\hline 7 & 50.9 & 100 & 5.66 & 566 & 2571.03 \\
\hline 8 & 52.1 & 100 & 5.66 & 566 & 2630.09 \\
\hline 9 & 56 & 100 & 5.66 & 566 & 2828.50 \\
\hline 10 & 60.2 & 100 & 5.66 & 566 & 3034.08 \\
\hline 11 & 64.8 & 120 & 5.95 & 714 & 3261.29 \\
\hline 12 & 68 & 120 & 5.95 & 714 & 3419.16 \\
\hline 13 & 71.4 & 120 & 5.95 & 714 & 3586.5 \\
\hline 14 & 76.6 & 120 & 5.95 & 714 & 3843.55 \\
\hline 15 & 81.2 & 120 & 5.95 & 714 & 40470.13 \\
\hline 16 & 86.1 & 140 & 6.24 & 873.6 & 4309.82 \\
\hline 17 & 88.6 & 140 & 6.24 & 873.6 & 4432.41 \\
\hline 18 & 88 & 140 & 6.24 & 873.6 & 4400.81 \\
\hline 19 & 88.2 & 140 & 6.24 & 873.6 & 4409.40 \\
\hline 20 & 87.8 & 140 & 6.24 & 873.6 & 4387.17 \\
\hline 21 & 88.9 & 160 & 6.59 & 1054.4 & 4437.20 \\
\hline 22 & 94.5 & 160 & 6.59 & 1054.4 & 4705.79 \\
\hline 23 & 95.5 & 160 & 6.59 & 1054.4 & 4748.1 \\
\hline 24 & 96.9 & 160 & 6.59 & 1054.4 & 4808.79 \\
\hline
\end{tabular}

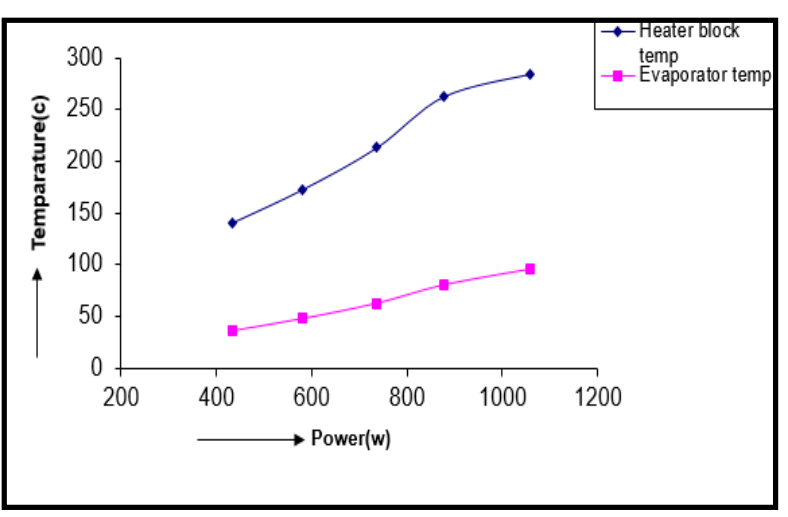

Fig. 5 Temperature Vs Power for Heat Pipe
Table 3 Results for Heat pipe

\begin{tabular}{|c|c|c|c|c|c|}
\hline \begin{tabular}{l}
0 \\
\multirow{\infty}{*}{} \\
$Z$ \\
Z
\end{tabular} & 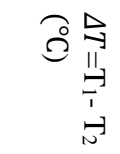 & 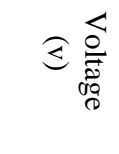 & 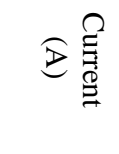 & 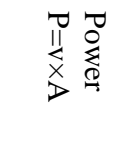 & $\xi^{\circ}$ \\
\hline 1 & 104 & 80 & 5.41 & 432.8 & 5264.75 \\
\hline 2 & 107.9 & 80 & 5.41 & 432.8 & 5459.3 \\
\hline 3 & 110.7 & 80 & 5.41 & 432.8 & 5598.89 \\
\hline 4 & 116 & 80 & 5.41 & 432.8 & 5862.92 \\
\hline 5 & 118.4 & 80 & 5.41 & 432.8 & 5982.33 \\
\hline 6 & 124.6 & 100 & 5.82 & 582 & 6290.43 \\
\hline 7 & 126.7 & 100 & 5.82 & 582 & 6394.67 \\
\hline 8 & 129.7 & 100 & 5.82 & 582 & 6543.48 \\
\hline 9 & 141.9 & 100 & 5.82 & 582 & 7147.32 \\
\hline 10 & 141.7 & 100 & 5.82 & 582 & 7137.53 \\
\hline 11 & 150.1 & 120 & 6.14 & 736.8 & 7552.22 \\
\hline 12 & 153.2 & 120 & 6.14 & 736.8 & 7705.02 \\
\hline 13 & 156.5 & 120 & 6.14 & 736.8 & 7842.1 \\
\hline 14 & 161.6 & 120 & 6.14 & 736.8 & 7118.42 \\
\hline 15 & 165.3 & 120 & 6.14 & 736.8 & 8302.31 \\
\hline 16 & 163.4 & 140 & 6.26 & 876.4 & 8206.88 \\
\hline 17 & 177.2 & 140 & 6.26 & 876.4 & 8883.86 \\
\hline 18 & 181.6 & 140 & 6.26 & 876.4 & 9098.91 \\
\hline 19 & 183 & 140 & 6.26 & 876.4 & 9167.34 \\
\hline 20 & 187.9 & 140 & 6.26 & 876.4 & 9406.53 \\
\hline 21 & 190 & 160 & 6.61 & 1057.6 & 9509.12 \\
\hline 22 & 193 & 160 & 6.61 & 1057.6 & 9655.39 \\
\hline 23 & 195.3 & 160 & 6.61 & 1057.6 & 9767.32 \\
\hline 24 & 203.2 & 160 & 6.61 & 1057.6 & 10151.83 \\
\hline
\end{tabular}

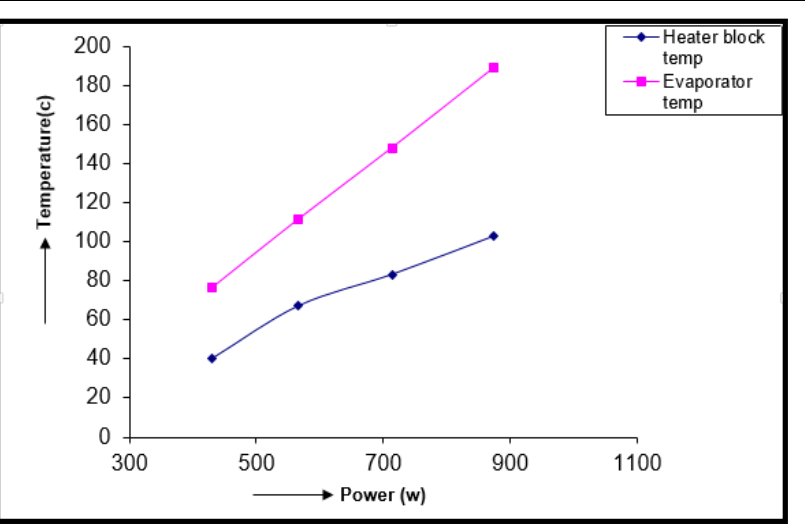

Fig. 6 Temperature Vs Power for Copper Pipe

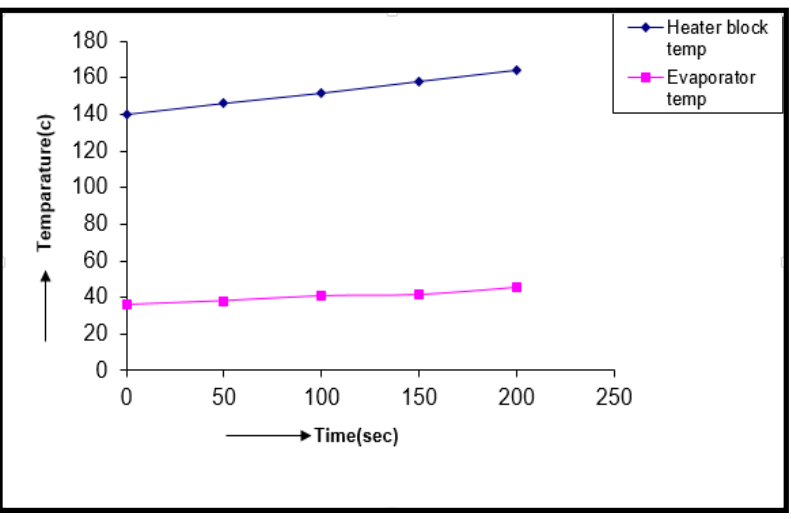

Fig. 7 Temperature Vs Time at 80V for Heat Pipe 


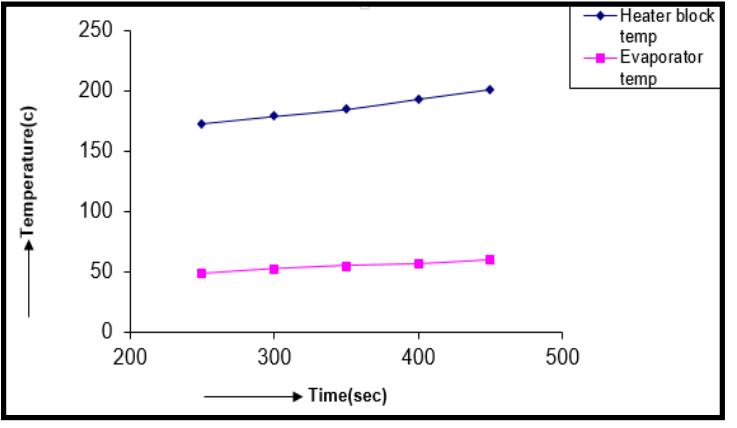

Fig. 8 Temperature Vs Time at 100V for Heat Pipe

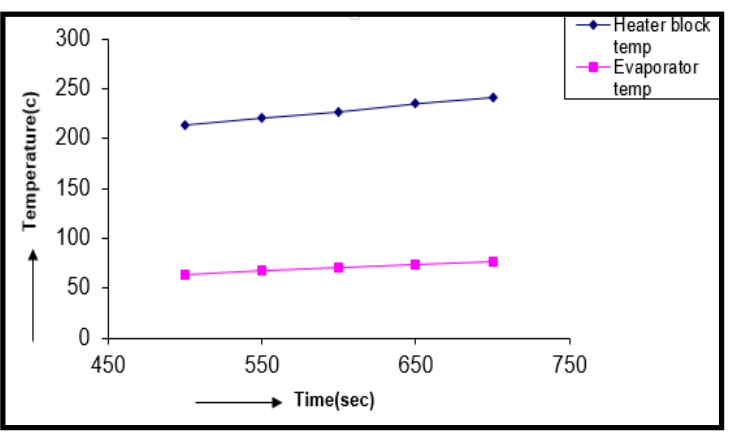

Fig. 9 Temperature Vs Time at $120 \mathrm{~V}$ for Heat Pipe

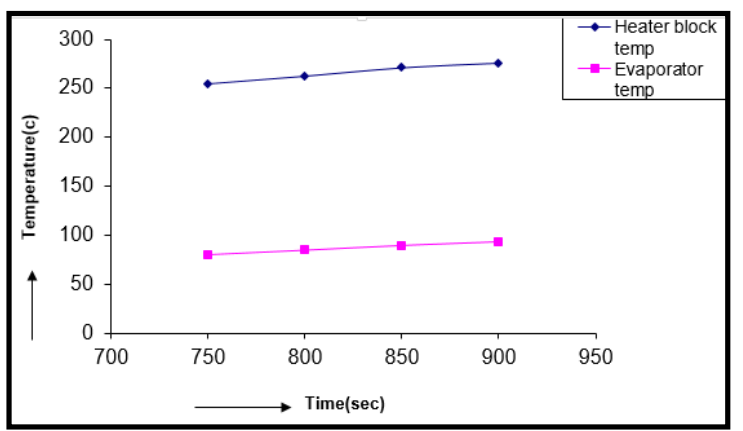

Fig. 10 Temperature Vs Time at 140V for Heat Pipe

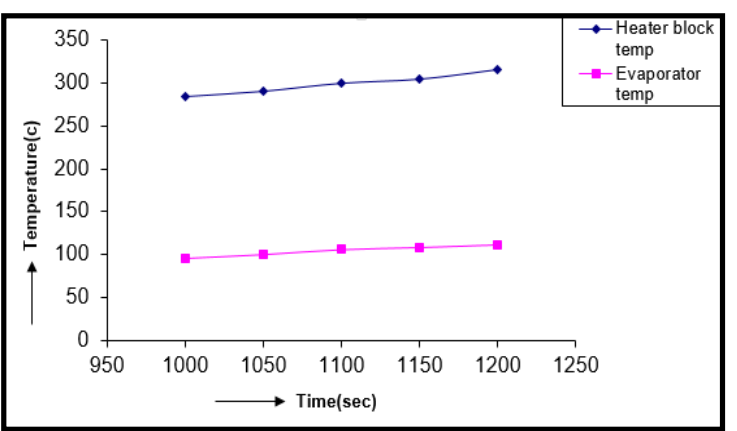

Fig. 11 Temperature Vs Time at 160V for Heat Pipe

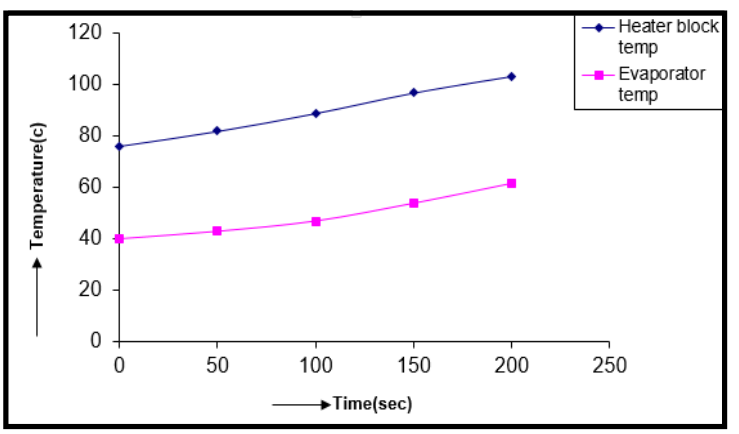

Fig. 12 Temperature Vs Time at 80V for Copper Pipe

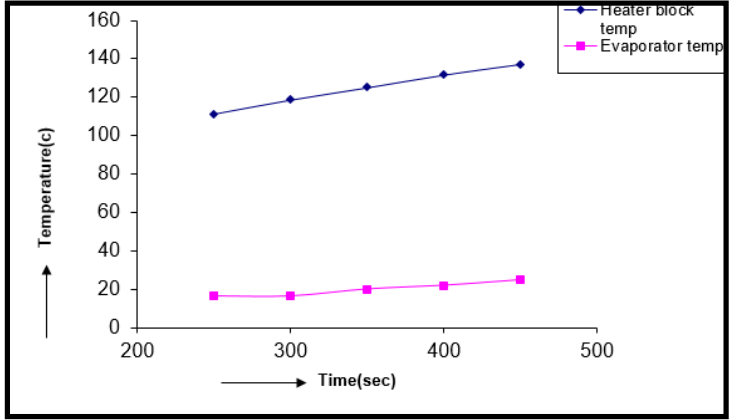

Fig. 13 Temperature Vs Time at 100V for Copper Pipe

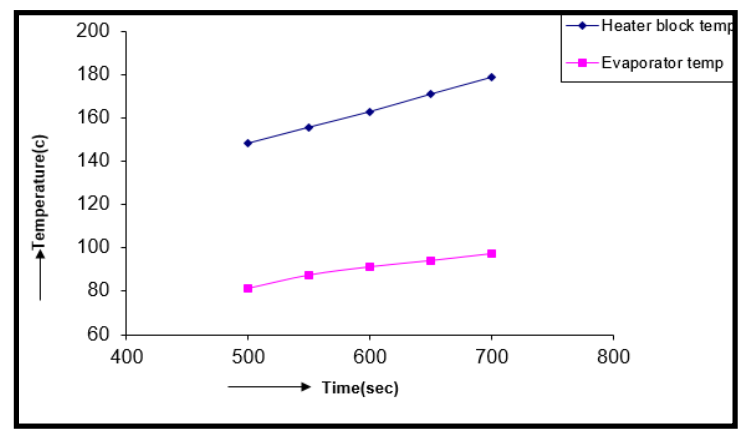

Fig. 14 Temperature Vs Time at 120V for Copper Pipe

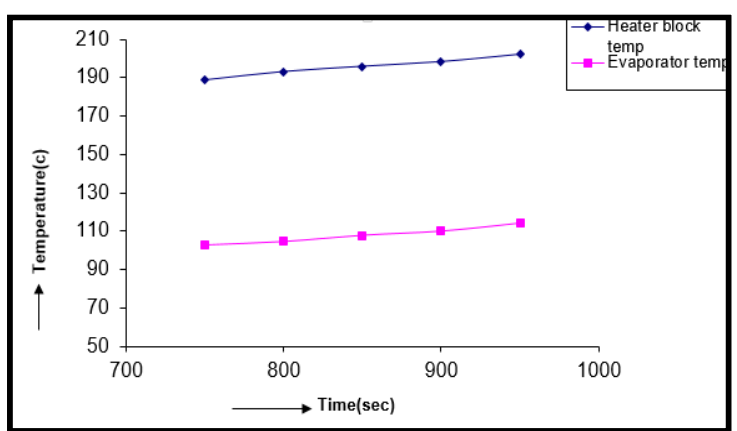

Fig. 15 Temperature Vs Time at 140V for Copper Pipe

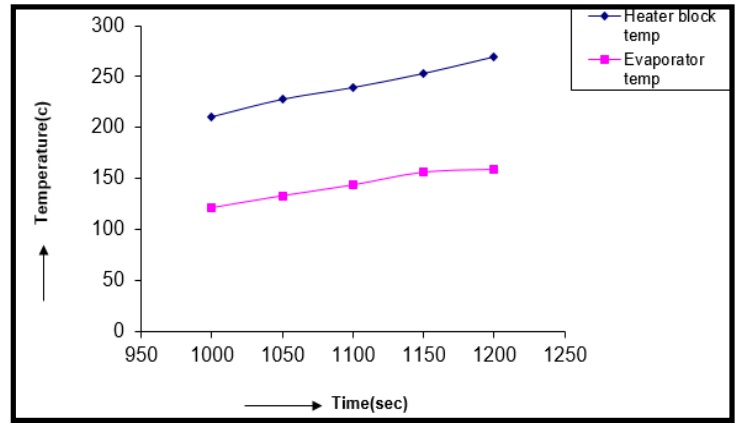

Fig. 16 Temperature Vs Time at 160V for Copper Pipe

\section{Discussion}

As it was necessary to vacuum the pipe perfectly for the best performance of the pipe that's why the pipe was sealed by gas welding. During this process the temperature was very high as a result the thermal characteristics of the wick material and the container were not remaining same. During the performance test the temperature was measured by laser thermometer as a result the temperature reading varies slightly. The rate of supplied cooling water was not uniform and the temperature of the supplied water varies as a result the value of temperature measured was not so accurate. From Fig. 5 \& Fig. 6 it is observed that the temperature of the evaporator end increases 
at a greater rate of the copper pipe than the heat pipe at different power level. Fig. 7-Fig. 11, shows the variation in temperature of the heater block and the evaporator section at $80 \mathrm{~V}, 100 \mathrm{~V}$, $120 \mathrm{~V}, 140 \mathrm{~V}, 160 \mathrm{~V}$ respectively of the heat pipe. Fig. 13-Fig. 16 shows the variation in temperature of the heater block and the evaporator section at $80 \mathrm{~V}, 100 \mathrm{~V}, 120 \mathrm{~V}, 140 \mathrm{~V}, 160 \mathrm{~V}$ respectively of the copper pipe. From this fig it is observed that at same input voltage the rise in temperature of heater block and evaporator section of heat pipe is less than that of copper pipe. From the figures it is also clear that rate of increase in temperature at heater block and evaporator section is slower than that of the copper pipe.

\section{Conclusion}

During the performance test the cooling water was supplied by a long pipe which directly connected to the source. The cooling water directly strikes on the condenser end of the heat pipe and as the supplied water temperature was changed because of the change in ambient temperature. So if we can ensure a constant rate of supply and if the supplied water temperature remains constant then a better performance may be achieved. From literature review it is known that heat pipes have attracted a lot of attention over the years. The ongoing work on heat pipes made using sintered copper felt as the wicking medium was extended to explore the possibility of more efficient heat pipe.

\section{Nomenclature}

\begin{tabular}{|clcl|}
\hline$T$ & :Temperature, ${ }^{\circ} \mathrm{C}$ & $L$ & : Length, $\mathrm{m}$ \\
$W$ & : Power, Watt & $D$ & : Diameter, $\mathrm{m}$ \\
$t$ & : Time, second & $A$ & : Area, $^{2}$ \\
$Q$ & : Heat, Joule/sec & $V$ & : Volume $^{3}$ \\
$V$ & : Voltage, Volt & $K$ & : Coefficient of heat $^{3}$ \\
$A$ & : Current, Ampere & $R$ & : Heat resistance \\
\hline
\end{tabular}

\section{References}

[1] Peterson GP. An introduction to heat pipes. Modeling, testing, and applications. Wiley Series in Thermal Management of Microelectronic and Electronic Systems, New York, Chichester: Wiley,|c1994. 1994.

[2] Odhekar DD, Harris DK. Experimental investigation of bendable heat pipes using sintered copper felt wick. InThermal and Thermomechanical Proceedings 10th Intersociety Conference on Phenomena in Electronics Systems, 2006. ITHERM 2006. 2006 May 30 (pp. 8-pp). IEEE.

[3] Mai T.Attachment of Listeria Monocytogenes to Austenitic Stainless Steel (Doctoral dissertation).

[4] Grady M. Coaxial Probe for High Temperature Dielectric Characterization (Doctoral dissertation).

[5] Ozisik MN. Heat transfer: a basic approach. New York: McGraw-Hill; 1985 Dec.

[6] Palkar A. An Experimental Investigation of Liquid Metal MHPs (Doctoral dissertation).
[7] Harris DK. "Experimental investigation of bendable heat pipes using sintered copper felt wick", Thermal and Thermomechanical Proceedings 10th Intersociety Conference on Phenomena in Electronics Systems 2006 ITHERM 2006, 2006.

[8] Dunn PD, Reay DA. Heat pipes, 3rd ed. Oxford Oxfordshire ; New York: Pergamon Press, 1982.

[9] Peterson GP. Experimental investigation of micro heat pipes in silicon wafers. Micromechanical Sensors, Actuators, and Systems, ASME. 1991;32.

[10]Lai A, Gillot C, Ivanova M, Avenas Y, Louis C, Schaeffer C, Fournier E. Thermal characterization of flat silicon heat pipes. InTwentieth Annual IEEE Semiconductor Thermal Measurement and Management Symposium (IEEE Cat. No. 04CH37545) 2004 Mar 11 (pp. 21-25). IEEE.

[11]Dunn P, Reay DA. "Practical Design Considerations" , Elsevier BV, 1982.

[12] Ong KS, Hamlaoui A. Experimental Observations of Water-filled and R134a-filled Thermosyphons Operating at Low Temperatures. JOURNAL OF ENERGY HEAT AND MASS TRANSFER. 2002;24(3):235-54.

[13] Noie-Baghban SH, Majideian GR. Waste heat recovery using heat pipe heat exchanger (HPHE) for surgery rooms in hospitals. Applied thermal engineering. 2000 Oct 1;20(14):1271-82.

[14]Liang TS, Hung YM. Experimental investigation on the thermal performance and optimization of heat sink with Ushape heat pipes. Energy Conversion and Management. 2010 Nov 1;51(11):2109-16.

[15]Zohuri B. Heat pipe design and technology: Modern applications for practical thermal management. Springer; 2016 Apr 28.

[16] Semena MG, Zaripov VK. Investigation of the effective thermal conductivity of metal-fiber wicks in lowtemperature heat pipes. Journal of engineering physics. 1977 Aug 1;33(2):911-6.

[17] Vasiliev LL, Kulakov AG, Filatova OS, Epifanov SV. Copper sintered powder wick structures of miniature heat pipes. InVI Minsk international seminar 'heat pipes, heat pumps, refrigerators. Minsk, Belarus 2005 Sep (pp. 12-15).

[18] Cengel YA. Introduction to thermodynamics and heat transfer, 1997. New York: MacGraw-Hill series in mechanical engineering.

[19] Wang Y, Han X, Liang Q, He W, Lang Z. Experimental investigation of the thermal performance of a novel concentric condenser heat pipe array. International Journal of Heat and Mass Transfer. 2015 Mar 1;82:170-8.

[20] Silverstein C. Design and technology of heat pipes for cooling and heat exchange. CRC press; 1992 Aug 1.

[21] Hossain ME. “ Construction and Performance test of Heat Pipe" Department of Mechanical Engineering, Khulna University of Engineering \& Technology, Bangladesh2008. 